\title{
Editorial
}

\section{Half a century of the Antarctic treaty}

$\mathrm{O}$ n 1 December 1959 twelve countries signed the Antarctic Treaty and ushered in a new era of international governance for the continent. Now, fifty years later, there are 47 countries, representing $65 \%$ of the global population, supporting the Treaty in a radically different world. How has the Treaty survived these changes - the Cold War, the arguments over mineral and biological resources, the apartheid regime in South Africa, the attacks in the United Nations and the expansion in membership? The answer is - remarkably well.

One major advantage has been the lack of any permanent inhabitants, allowing governance to develop without worries about the next election. The value of consensus has been that everyone has moved forward together, and although this has proved frustratingly slow, it has ensured a level of stability rare elsewhere in the world.

Treaty membership now embraces greater diversity. Amongst the Consultative and Acceding Parties there are the active nations in each group and the inactive, the claimant and the nonclaimant states, the scientifically strong and the scientifically weak, those for whom the Antarctic is politically important and those who barely recognize its value, the rich countries and the poor. Importantly there are those states that make the agenda and those who are happy to follow. The science agenda is, at least in part, determined by science outputs and the top ten ranking at present is - USA, UK, Australia, Germany, Italy, France, Japan, New Zealand, Russia and Spain. SCAR also has a major input here. Setting the political agenda has been more complex but on the basis of ATCM papers submitted the USA, UK, Argentina, Chile, Australia, New Zealand and Norway have clearly played major roles along more recently with Germany and the Netherlands. Some countries have barely succeeded either scientifically or politically in this forum and one wonders why it has seemed important to them to continue with such a costly activity?

Antarctica constitutes one of the "international spaces" or "global commons" that are the joint heritage of everyone. The others are the High Seas and the seabed, the atmosphere and Outer Space. Governance rules have been developed for several of these but without being able either to attract the agreement of all countries or to successfully resolve the problems caused by national agendas. The Antarctic has fewer adhering states (47) than either the Law of the Sea (157) or the Outer Space Treaty (99) and it is not clear why. Why would Eire, Saudi Arabia, Mexico, Egypt and Thailand for example see Outer Space as more important than Antarctica? Are they living on another planet? Why would land-locked countries like Paraguay, Bolivia, Mongolia, Armenia, and Moldova sign up to a Law of the Sea but not to the Antarctic Treaty?

There are positive lessons from the Antarctic Treaty System on how to use science as a key element of decision making, on how to reach agreements across cultures and political systems, and how to try and manage resources in a sustainable way. Equally there are the negative features of a long period of secrecy, the decades of failure to establish a secretariat, the duplicity of some CCAMLR nations, etc. Politics was ever thus.

During these fifty years Antarctic science has moved forward enormously, taking the continent from an unknown backwater to centre stage in our models of a future Earth driven by climate change. Governance through the Treaty has been and continues to be of crucial importance in making this possible. This anniversary is not just a celebration for politicians and diplomats - it is for scientists as well!

DAVID W.H. WALTON 